Article

\title{
Comparative Adhesion, Ageing Resistance, and Surface Properties of Wood Plastic Composite Treated with Low Pressure Plasma and Atmospheric Pressure Plasma Jet
}

\author{
Andrés Jesús Yáñez-Pacios and José Miguel Martín-Martínez * (iD \\ Adhesion and Adhesives Laboratory, Department of Inorganic Chemistry, University of Alicante, \\ 03080 Alicante, Spain; andresjesus.yanez@ua.es \\ * Correspondence: jm.martin@ua.es; Tel.: +34-965-903-977; Fax: +34-965-909-416
}

Received: 4 May 2018; Accepted: 8 June 2018; Published: 9 June 2018

\begin{abstract}
Wood plastic composites (WPCs) have poor adhesion properties due to their high surface concentration in non-polar polymers. In this work, two different plasma surface treatments, low pressure plasma (LPP) and atmospheric pressure plasma jet (APPJ), are proposed to increase the surface energy and adhesion property of WPC made with polyethylene (PE-WPC). After optimizing the conditions for each plasma surface treatment, the surface modifications and adhesion of PE-WPC treated with LPP and APPJ were compared. The optimal surface modifications of PE-WPC were obtained by treatment with Argon (Ar):Oxygen $\left(\mathrm{O}_{2}\right)$ LPP for $90 \mathrm{~s}$, and with air APPJ by using a plasma nozzle-WPC surface distance of one centimeter and speed of platform of one meter per minute. Both plasma treatments produced similar chemical modifications and surface energies on the PE-WPC surface. The ablation was more important for $\mathrm{Ar}: \mathrm{O}_{2} \mathrm{LPP}$ treatment, and the air APPJ treatment produced more extensive chemical modifications and more homogeneously removal of the wood component of the surface, rendering the polymer surface smoother. Adhesion of PE-WPC was similarly improved by treatment with both plasmas, from $56 \mathrm{~N} / \mathrm{m}$ in the as-received to $92-102 \mathrm{~N} / \mathrm{m}$ in the plasma treated PE-WPC joints. The influence of ageing at $24{ }^{\circ} \mathrm{C}$ and $40 \%$ relative humidity of the adhesive joints made with PE-WPC surface and treated with Ar: $\mathrm{O}_{2}$ LPP and APPJ plasmas was studied. In the joints made with plasma-treated PE-WPC aged under open air for more than one day, the adhesion decreased. An adhesive strength near to that of the joint made with the as-received PE-WPC was obtained after six days. However, if the adhesive joint was created immediately after plasma treatment and peeled at different times, the adhesion was maintained and even increased, and the hydrophobic recovery of the plasma-treated PE-WPC surface was inhibited.
\end{abstract}

Keywords: wood plastic composite; surface treatment; low pressure plasma; atmospheric pressure plasma jet; surface energy; adhesion; ageing

\section{Introduction}

Wood plastic composites (WPCs) are alternative materials to wood, with improved mechanical properties and enhanced outdoor resistance. WPCs are made of wood flour, polymer matrix, and additives, such as lubricants, biocides, and stabilizers. The polymer is added in amounts of 30 to $70 \mathrm{wt} \%$; the most common polymers are polyethylene, polypropylene, or poly (vinyl chloride) [1]. The additive content is usually lower than five wt \% and they are intended to increase the compatibility between the polar wood flour and the non-polar polymer components of the WPC.

During processing, the surface of the WPC is enriched with non-polar polymer and, consequently, its surface energy is low and its adhesion is poor. Due to the poor adhesion of WPCs, they cannot 
be joined with adhesives and they cannot be painted, colored, or decorated with paints or coatings. The actual joining procedures of WPC include mechanical interlocking, anchoring to metallic structural frame, and the use of nails. These procedures are limited in WPCs with complicated geometric shapes, and the use of adhesives would solve this limitation. Furthermore, WPCs are currently colored by adding the dye or the colorant during WPC processing, complicating the creation of solid colors [2]. The application of surface treatments can increase the adhesion of WPC to adhesives and coatings.

Several physical and chemical surface treatments have been proposed in the literature to improve the surface energy and/or the adhesion of different WPCs [3], including immersion in chromic acid, mechanical abrasion, and treatment with flame [4-7]. The surface treatment of WPCs with chromic acid was the most effective due to the chemical modifications produced on the surface, but this surface treatment is not environmentally friendly so new surface treatments must be developed. Gramlich et al. [1] established that surface treatment with flame, water, or combinations of both improved the shear strength of adhesive joints made with WPC made with polyolefin but not as much as achieved with chromic acid treatment. Yáñez-Pacios and Martín-Martínez [8] proposed surface treatment with ultraviolet (UV) and ozone for improving the surface energy and peel strength of WPC. The increase in adhesion was more noticeable by increasing the UV radiation dose.

Because WPCs are made of wood flour and polyolefin, during processing, their outermost surfaces are enriched in the polyolefin component. Therefore, for improving the adhesion properties of the WPCs, the same surface treatments for improving the adhesion of polyolefin can be applied. The most relevant existing literature has demonstrated that surface treatments with low pressure and atmospheric plasmas were the most effective for improving the adhesion of polyethylene and polypropylene polymers [9-16]. Both nitrogen and oxygen low-pressure plasmas have been successfully used for improving the adhesion of polyethylene polymer [10-12], which was mainly ascribed to surface oxidation. Different atmospheric pressure plasmas have been proposed for improving the adhesion of polyethylene and polypropylene polymers [13-16] and the improved adhesion was ascribed to the creation of a carbon-oxygen polar group on the polyolefin surface. Therefore, surface treatment with low pressure and/or atmospheric pressure plasmas should also increase the adhesion of WPC. In fact, some studies have demonstrated the usefulness of the plasma treatment for improving the surface energy and polarity of different WPCs but most of them did not consider the adhesion property.

Different atmospheric pressure plasma surface treatments for WPCs have been proposed in the literature. Moghadamzadeh et al. [6] used corona discharge surface treatment to effectively improve the surface polarity and shear strength of joints made with high-density polyethylene-based WPC and two-component epoxy adhesive. Along the same lines, Akhtarkhavari et al. [7] proposed the use of corona discharge surface treatment for improving the paintability and the adhesion of WPC made with polyethylene. Several additional studies confirmed that corona discharge surface treatment improved the adhesion of WPCs, mainly due to surface oxidation [17-19]. However, this treatment was not effective in avoiding hydrophobic recovery [17], as the surface modifications on the WPC surface were lost over time and the shear bonding strength decreased with ageing. Other kinds of atmospheric pressure plasmas have been proposed for the surface treatment of WPCs. Wolkenhauer et al. [20] treated polyethylene-based WPC with dielectric barrier discharge to produce chemical modifications, increase surface energy, and improve adhesion. Liu et al. [21] and Hünnekens et al. [22] obtained similar results, confirming the effectiveness of atmospheric plasmas on the improvement of the adhesion of WPC. Different air- or oxygen-forced atmospheric plasmas have been proposed for improving the surface properties of polyethylene and polypropylene based WPCs [23-25], and enhanced wettability and improved adhesion were obtained, irrespective of the polymer matrix in the WPC.

Low pressure plasma surface treatments for WPCs have scarcely been studied in the period 2008 to 2018. Gupta and Laborie [26] compared the effectiveness of several surface treatments for the surface activation of different WPCs, and they found that the oxygen low pressure plasma surface treatment notably improved the initial adhesion. Furthermore, the treatment with oxygen low-pressure 
plasma improved the wettability, enhanced the surface roughness, and increased the interfacial adhesion of the WPCs. Air or oxygen low-pressure plasma surface treatments produced crosslinking, chain scission, ablation, oxidation, and even surface roughening of polymers and WPCs, and these surface modifications contributed to the improvement of their adhesion [12,26,27]. In another study, Yáñez-Pacios and Martín-Martínez [28] used Ar: $\mathrm{O}_{2}$ low-pressure plasma for improving the surface properties and adhesion of polyethylene-based WPC.

The surface modifications on polyethylene produced by low pressure plasma have been shown to be lost by increasing the time after treatment due to ageing and/or hydrophobic recovery [29-31]. Several publications [32-34] studied the stability of surface modifications on different non-polar polymers treated with low-pressure plasma. They concluded that immersion in polar liquids and short-term treatment increased the stability of the surface modifications with time. However, to the best of our knowledge, the stability of the surface modifications of low-pressure plasma-treated WPCs has not yet been studied. On the other hand, only one study [35] addressed the ageing of atmospheric pressure plasma-treated WPCs made with polyethylene and polypropylene. Ageing studies were completed by storing the surface-treated WPC pieces at different temperatures $\left(20\right.$ or $\left.60^{\circ} \mathrm{C}\right)$ and relative humidity $(0,65$, and $75 \%)$. They concluded that ageing time was not the main parameter determining ageing; the relative humidity and the temperature affected more the loss of the surface modifications over time. On the other hand, the increase in the time between the surface treatment and the coating or gluing of the treated WPCs caused a decrease in the wettability [35].

Although some publications are related to the effects produced by the surface treatment of WPCs with different kind of plasmas, neither a comparison between the effectiveness of treatment with low-pressure and atmospheric pressure plasmas of WPCs, nor a comparative study of the influence of ageing with time on their adhesion, have been performed. Therefore, in this work, two different plasma surface treatments ( $\mathrm{Ar}: \mathrm{O}_{2}$ low pressure plasma and air atmospheric pressure plasma jet) of WPC made with polyethylene were optimized and compared, and the changes in the surface properties, topography, adhesion, and ageing resistance over time were studied.

\section{Materials and Methods}

\subsection{Wood Plastic Composite}

Commercial high-density polyethylene-based WPC (PE-WPC) made by extrusion was used. PE-WPC was supplied by Condepols (Jaén, Spain) in the form of alveolar boards that were cut into pieces of $3 \times 7 \mathrm{~cm}^{2}$ for surface treatment and characterization. PE-WPC has high wood content (43 wt \% obtained by thermal gravimetric analysis experiments [25]).

\subsection{Plasma Surface Treatments}

\subsubsection{Ar: $\mathrm{O}_{2}$ Low Pressure Plasma (LPP)}

PE-WPC was surface treated with radiofrequency $(13.56 \mathrm{MHz})$ low-pressure plasma in a Digit Concept NT1 (BSET EQ, Antioch, CA, USA) plasma reactor. The plasma reactor is made of stainless steel chamber with aluminum shelves. The side walls of the plasma reactor have shelf guides to slide the shelves into the back tracks. Brass and aluminum electrode buss bars are placed on the back wall of the plasma reactor, the power shelf is plugged into the brass electrode bar, and the ground shelf is plugged into the aluminum buss electrode (Figure 1). Thus, depending on the connection of the power and ground shelves into the electrode buss bars, different configurations of the plasma reactor can be obtained. The "direct" configuration of the shelves, in which the PE-WPC is placed over the power shelf that is located below the ground shelf, was used in this study. A mixture of argon:oxygen (2:1, vol/vol; oxygen flow: 50 standard $\mathrm{cm}^{3} / \mathrm{min}$; argon flow: 110 standard $\mathrm{cm}^{3} / \mathrm{min}$ ) was used to generate the plasma. This specific gas combination was selected due to its effectiveness in avoiding the surface migration of low molecular weight species as demonstrated in previous studies $[28,36]$. 
Ar: $\mathrm{O}_{2}$ LPP should produce an adequate balance between the chemical (mainly oxidation) and physical (mainly ablation) modifications produced on the surface of different polymers. The power was set to $200 \mathrm{~W}$, the residual pressure was 800 mbar, and the treatment time ranged between 20 and $90 \mathrm{~s}$. Because PE-WPC contains relatively significant amounts of moisture, to avoid the influence of the desorbing species, including water and additives, from the PE-WPC during LPP treatment, the residual pressure used in this study was higher than usual.

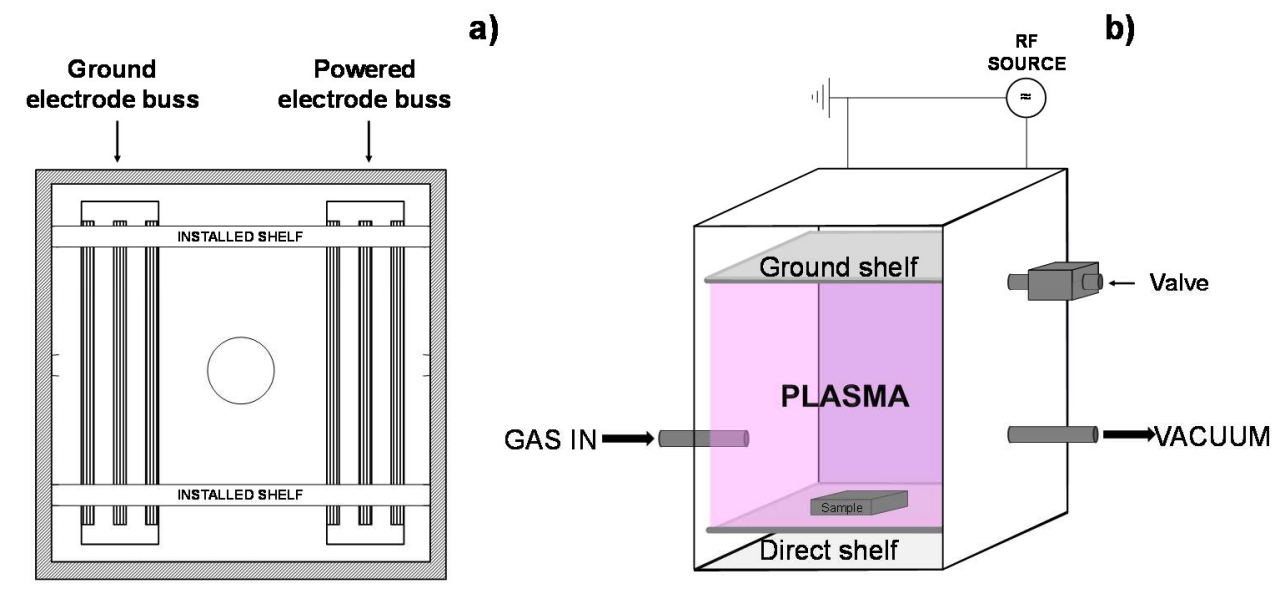

Figure 1. Scheme of low-pressure plasma (LPP) reactor used for surface treatment of polyethylene wood plastic composite (PE-WPC): (a) chamber scheme and (b) direct configuration scheme.

\subsubsection{Air Atmospheric Pressure Plasma Jet (APPJ)}

PE-WPC was surface treated in an APPJ Openair FG1001 plasma generator (Plasma Treat GmbH, Steinhagen, Germany) with a RD1004 rotary nozzle with an opening ring of $4 \mathrm{~mm}$ diameter. The plasma was generated inside the nozzle by a non-equilibrium discharge using $\mathrm{kHz}$ excitation (voltage of $300 \mathrm{~V}$ and current of 8.6 A) and expelled through a circular orifice onto the PE-WPC surface. The PE-WPC sample was placed on an electronically controlled speed platform placed below the plasma jet (Figure 2). Compressed synthetic air (Air Liquide, Madrid, Spain) was used for generating the plasma, the pressure of the compressed air was set to 2.5 bars, and the air flow was 114 normal L/min. The plasma was expelled through the rotary nozzle and the speed of the exit of the plasma was controlled by setting the rotational speed to $1900 \mathrm{rpm}$ and the angle shot to $14^{\circ}$. The PE-WPC surface-nozzle distance was set to $1 \mathrm{~cm}$, and the treatment time was varied by changing the speed of the electronically controlled platform on which the PE-WPC sample was placed, between 1 and $8 \mathrm{~m} / \mathrm{min}$.

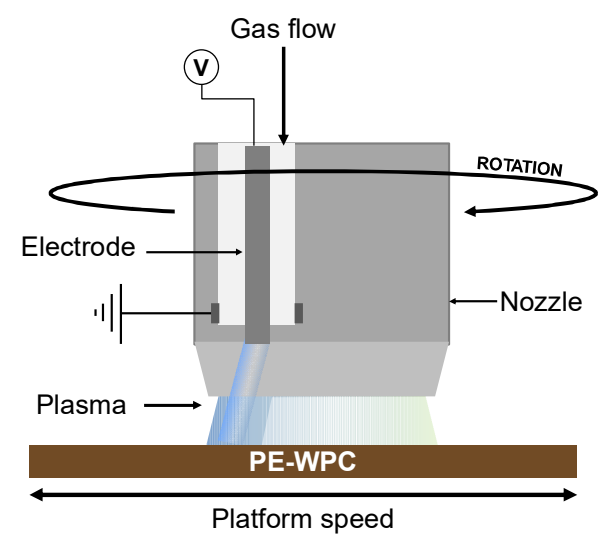

Figure 2. Scheme of atmospheric pressure plasma jet (APPJ) system used for the surface treatment of PE-WPC. 


\subsection{Characterization Techniques}

\subsubsection{Attenuated Total Reflectance Infrared Spectroscopy (ATR-IR)}

The chemical modifications produced in the PE-WPC surface treated with different plasmas were assessed by attenuated total reflectance infrared spectroscopy (ATR-IR) in an Alpha spectrometer (Bruker Optiks, Etlinger, Germany). A germanium prism was used. The incidence angle of the infrared (IR) beam was $45^{\circ}$ and 60 scans were obtained and averaged with a resolution of $4 \mathrm{~cm}^{-1}$. Under these experimental conditions, a depth of about $1 \mu \mathrm{m}$ of the PE-WPC surface was analyzed.

\subsubsection{Contact Angle Measurements}

The wettability of the as-received and plasma-treated PE-WPC surface was estimated by contact angle measurements at $25^{\circ} \mathrm{C}$ in a Ramé-Hart 100 goniometer (Netcong, NJ, USA). Two test liquids of different polarity, bidistilled and deionized water (polar liquid) and diiodomethane (non-polar liquid), were used. Drops of $4 \mu \mathrm{L}$ of test liquid were placed on the as-received and plasma-treated PE-WPC surface and the contact angles were measured immediately after drop deposition. Due to the surface roughness of the PE-WPC, the tilting plate method was used to measure the advancing and receding angles. Because the contact angle values obtained by the sessile drop method agreed well with the advancing contact angle values, the advancing contact angle values were used. At least five drops of each liquid placed in different locations on the PE-WPC surface were measured and the contact angle values were averaged.

From the advancing contact angle values obtained with water and diiodomethane, the surface energy $\left(\gamma_{S}\right)$ and their dispersive $\left(\gamma_{S}^{d}\right)$ and polar $\left(\gamma_{S}^{p}\right)$ components of the as-received and plasma-treated PE-WPC surface were obtained. The surface energies and their components were estimated by means of Owens-Wendt approach, as shown in Equation (1):

$$
\left(1+\cos \theta_{i}\right)\left(\gamma_{i}^{d}+\gamma_{i}^{p}\right)=2\left(\sqrt{\gamma_{i}^{d} \gamma_{S}^{d}}+\sqrt{\gamma_{i}^{p} \gamma_{S}^{p}}\right)
$$

where $\theta_{i}$ is the advancing contact angle value, $\gamma_{i}$ is the surface tension of the test liquid, and the superscripts $p$ and $d$ indicate the polar and dispersive components of the surface tension of the test liquid or the surface energy of PE-WPC, respectively. The components of the surface tensions of the test liquids were $\gamma_{\text {water }}^{p}=51 \mathrm{mN} / \mathrm{m}$ and $\gamma_{\text {water }}^{d}=21.8 \mathrm{mN} / \mathrm{m}$ for water, and $\gamma_{\mathrm{CH}_{2} I_{2}}^{p}=0 \mathrm{mN} / \mathrm{m}$ and $\gamma_{\mathrm{CH}_{2} I_{2}}^{d}=50.8 \mathrm{mN} / \mathrm{m}$ for diiodomethane.

\subsubsection{Scanning Electron Microscopy (SEM)}

The changes produced by plasma treatments on the PE-WPC topography were assessed with a Jeol JSM-840 microscope (Jeol Ltd., Tokyo, Japan) working at $15 \mathrm{kV}$. To obtain micrographs with good contrast, prior to being introduced into the SEM chamber, the samples were gold coated in $\mathrm{Au} / \mathrm{Pd}$ Balzers metallizer SCD 004 (Oerlikon Surface Solutions, Balzers, Liechtenstein, Germany).

\subsubsection{Thermogravimetric Analysis (TGA)}

The extent of ablation produced by plasma treatment of PE-WPC was quantified by the weight loss produced during the treatment. Thermogravimetric analysis (TGA) was used to determine the variation in weight as a function of the temperature in the as-received and plasma-treated PE-WPC. TGA experiments were carried out using TGA TA Q500 equipment (TA Instruments, New Castle, DE, USA). A total of $10 \mathrm{mg}$ of the sample was placed in platinum crucible and heated from room temperature to $800{ }^{\circ} \mathrm{C}$ using a heating rate of $10^{\circ} \mathrm{C} / \mathrm{min}$ under nitrogen atmosphere (gas flow: $60 \mathrm{~mL} / \mathrm{min}$ ). 


\subsubsection{Adhesion Measurements}

Adhesive properties were assessed by $180^{\circ}$ peel strength of as-received or plasma-treated PE-WPC/Magic Scotch ${ }^{\circledR}$ acrylic adhesive tape joints. Rectangular pieces of PE-WPC, $3 \times 7 \mathrm{~cm}^{2}$, and rectangular pieces of Magic Scotch ${ }^{\circledR}$ tape (3M, Saint Paul, MN, USA) of $18 \times 1.9 \mathrm{~cm}^{2}$ were used. The adhesive tape was $11 \mathrm{~cm}$ longer than that of PE-WPC to facilitate the attachment to the upper clamp of the test machine for the $180^{\circ}$ peel test (Figure 3). Adhesive joints were created by placing the adhesive tape over the PE-WPC, and 30 consecutive passes with $2 \mathrm{~kg}$ rubber roller were carried out to create intimate contact between the PE-WPC surface and the acrylic adhesive tape. One hour after joint formation, the $180^{\circ}$ peel test was carried out in a TA-XT2i texture analyzer (Stable Micro Systems, Godalming, UK). The peeling rate was $10 \mathrm{~mm} / \mathrm{s}$.

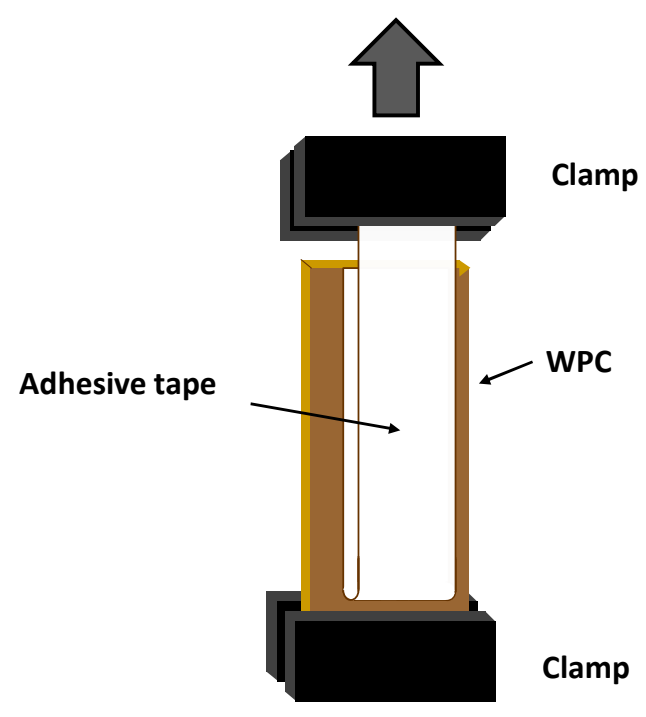

Figure 3. Scheme of test sample for $180^{\circ}$ peel test of the PE-WPC/acrylic adhesive tape joint [8].

The variation in the adhesion of the plasma-treated PE-WPC/acrylic adhesive tape joints was monitored at $24{ }^{\circ} \mathrm{C}$ and $40 \%$ relative humidity for different times (ageing test). Two different ageing tests were carried out: (1) The plasma-treated PE-WPC was exposed at $24{ }^{\circ} \mathrm{C}$ and $40 \%$ relative humidity and the joints were created at different times after plasma treatment (Figure 4a); (2) Immediately after treatment, the plasma-treated PE-WPC was joined to the adhesive acrylic tape and left at $24{ }^{\circ} \mathrm{C}$ and $40 \%$ relative humidity. The $180^{\circ}$ peel tests were carried out at different times after joint formation (Figure $4 b$ ).

a)

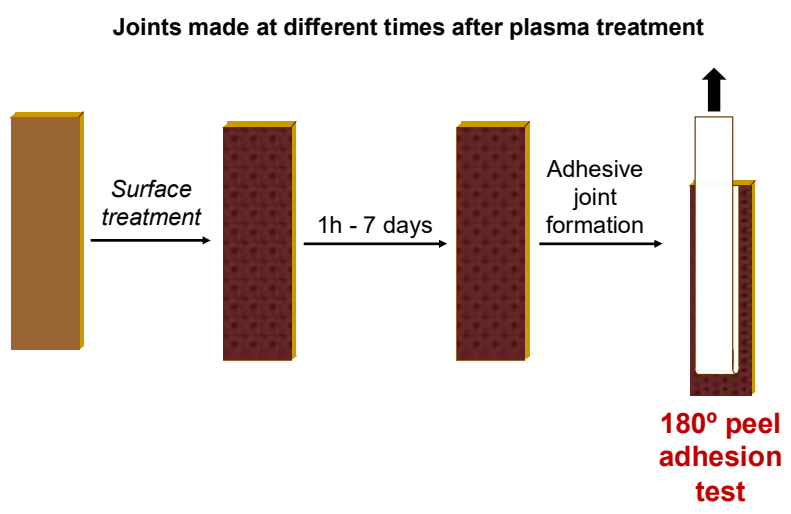

Figure 4. Cont. 
b)

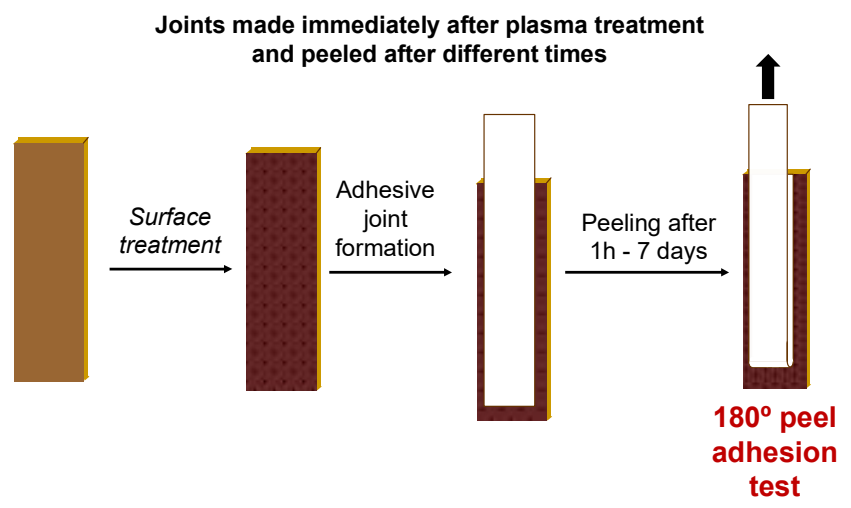

Figure 4. Scheme of the ageing tests of plasma treated PE-WPC/acrylic adhesive tape joints.

\section{Results and Discussion}

\subsection{Ar: $\mathrm{O}_{2}$ Low Preure Plasma (LPP) Treatment of PE-WPC}

The optimization of the low-pressure plasma surface treatment of PE-WPC was previously studied by Yáñez-Pacios and Martín-Martínez [28], employing direct and secondary downstream shelves configurations. In this study, the direct shelves configuration was used for surface treatment of PE-WPC with Ar: $\mathrm{O}_{2}$ LPP and the treatment time varied between 20 and $90 \mathrm{~s}$. The chemical modifications produced by Ar: $\mathrm{O}_{2}$ LPP treatment of PE-WPC were assessed by ATR-IR spectroscopy. Figure 5a shows the $2800-3000 \mathrm{~cm}^{-1}$ region of the ATR-IR spectra of $\mathrm{Ar}: \mathrm{O}_{2}$ LPP-treated PE-WPC. The short-term treatment decreases the intensities of the C-H bands at 2842, 2910, and $2942 \mathrm{~cm}^{-1}$ due to polyethylene, indicating that the polyethylene was removed from the surface due to the dominance of ablation. However, the increase in the treatment time to $40 \mathrm{~s}$ enriched the polyethylene of the treated PE-WPC surface, and for a longer time, similar ATR-IR spectra were obtained. Figure $5 \mathrm{~b}$ shows the 1300-1800 $\mathrm{cm}^{-1}$ region of the ATR-IR spectra of Ar: $\mathrm{O}_{2}$ LPP-treated PE-WPC. The short-time treatment decreased the intensity of the polyethylene bands at $1373-1456 \mathrm{~cm}^{-1}$ and decreased the intensity of the $\mathrm{C}=\mathrm{O}$ group at $1734 \mathrm{~cm}^{-1}$ due to the wood, indicating the removal of polyethylene and wood material from the surface. The treatment of PE-WPC with Ar: $\mathrm{O}_{2} \mathrm{LPP}$ for $40 \mathrm{~s}$ increased the intensities of both wood and polyethylene bands, and several additional low intensity $\mathrm{C}=\mathrm{O}$ bands at $1670-1720 \mathrm{~cm}^{-1}$ were observed due to polymer oxidation. When the surface treatment was carried out for more than $40 \mathrm{~s}$, all ATR-IR spectra were nearly the same and they showed a lower degree of oxidation because ablation prevailed over the surface oxidation.

The chemical modifications on the Ar: $\mathrm{O}_{2}$ LPP-treated PE-WPC surface should modify its wettability. Figure 6 shows the variation in the water contact angle values of the $\mathrm{Ar}_{2} \mathrm{O}_{2}$ LPP-treated PE-WPC surface as a function of the treatment time. The Ar: $\mathrm{O}_{2} \mathrm{LPP}$ surface treatment for $20 \mathrm{~s}$ noticeably decreased the water contact angle value (from $105^{\circ}$ in the as-received PE-WPC to $47^{\circ}$ ), and the wettability increased more when the treatment was carried out for $40 \mathrm{~s}$. For longer treatment times, similar wettability values (water contact angle of $16-18^{\circ}$ ) were obtained. Therefore, the $\mathrm{Ar}: \mathrm{O}_{2} \mathrm{LPP}$ treatment for $20 \mathrm{~s}$ increased the wettability of the PE-WPC surface due to the removal of polyethylene and the oxidation produced for short times of treatment. For Ar: $\mathrm{O}_{2} \mathrm{LPP}$ treatment longer than $40 \mathrm{~s}$, ablation was mainly produced. 


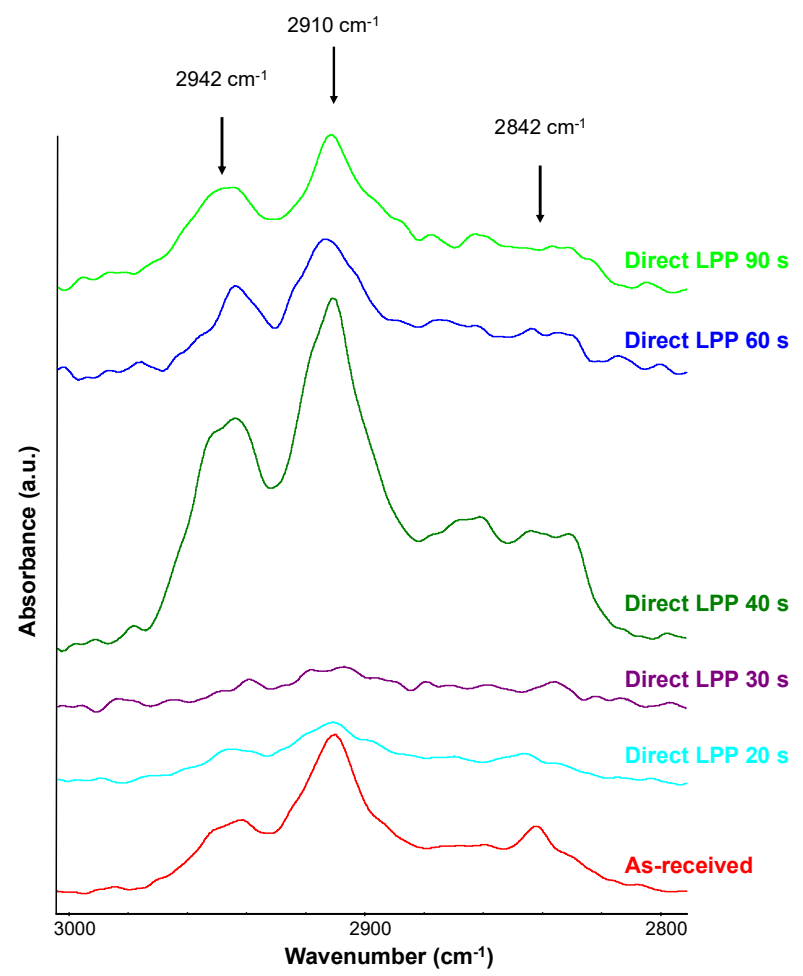

(a)



(b)

Figure 5. (a) Region of $2800-3000 \mathrm{~cm}^{-1}$ of the Attenuated Total Reflectance Infrared Spectroscopy (ATR-IR) spectra of the as-received and Ar: $\mathrm{O}_{2}$ LPP treated PE-WPC for different times. A germanium prism was used; (b) Region of $1300-1800 \mathrm{~cm}^{-1}$ of the ATR-IR spectra of the as-received and Ar: $\mathrm{O}_{2}$ LPP-treated PE-WPC for different times. 


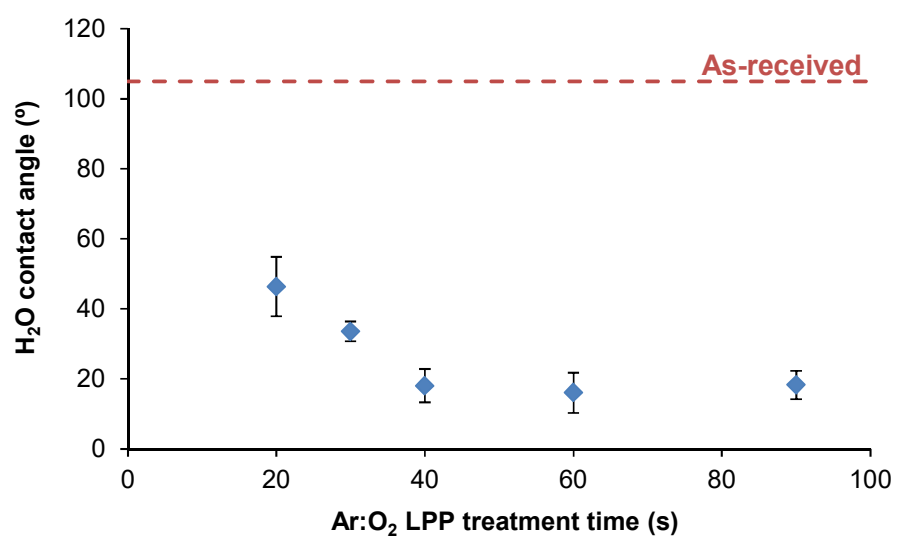

Figure 6. Variation in the water contact angle at $25{ }^{\circ} \mathrm{C}$ of the $\mathrm{Ar}: \mathrm{O}_{2}$ LPP-treated PE-WPC as a function of treatment time. The dashed line corresponds to the water contact angle of the as-received PE-WPC.

Figure 7 shows the evolution in the surface energy and its polar and dispersive components of the Ar: $\mathrm{O}_{2}$ LPP surface treated PE-WPC as a function of treatment time. The surface energy of the as-received PE-WPC was $39.5 \mathrm{~mJ} / \mathrm{m}^{2}$ and corresponded to the dispersive component only. The treatment of PE-WPC with Ar: $\mathrm{O}_{2}$ LPP increased the surface energy, the increase was mainly due to the polar component. The increase in the surface energy and its polar component were produced up to a treatment time of $40 \mathrm{~s}$; the surface energy was similar for longer times. All Ar: $\mathrm{O}_{2} \mathrm{LPP}$ surface-treated PE-WPC for different times showed a similar dispersive component of the surface energy. These findings agree well with the results of the ATR-IR spectroscopy.

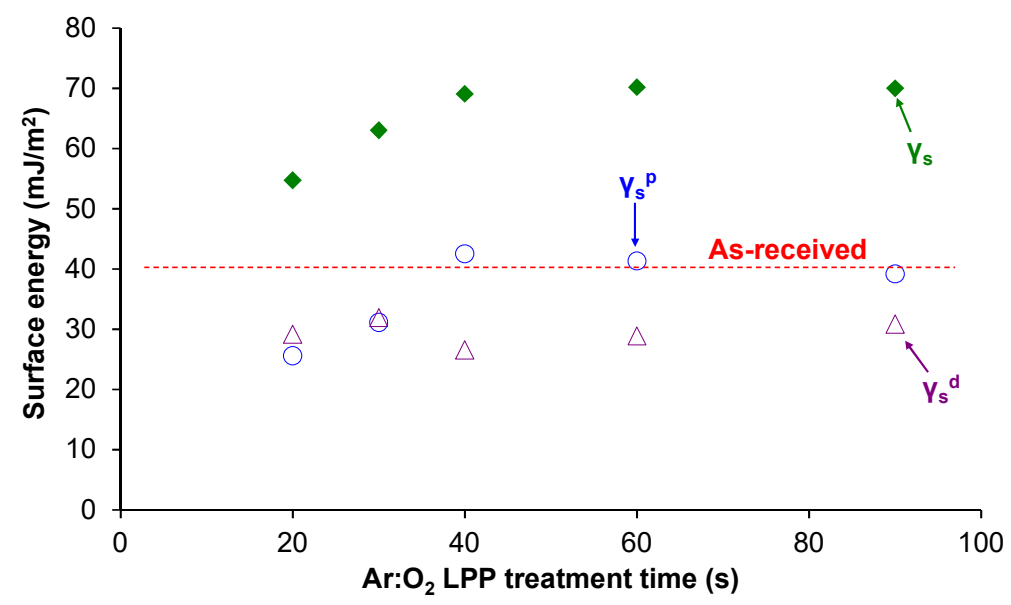

Figure 7. Variation in the surface energy $\left(\gamma_{s}\right)$ and their polar $\left(\gamma_{s}^{p}\right)$ and dispersive $\left(\gamma_{s}^{d}\right)$ components of the Ar: $\mathrm{O}_{2}$ LPP-treated PE-WPC as a function of treatment time. The dashed line corresponds to the surface energy of the as-received PE-WPC that only corresponds to the dispersive component.

The changes in the topography of the PE-WPC treated with Ar: $\mathrm{O}_{2} \mathrm{LPP}$ were assessed via SEM microscopy. The SEM micrographs of the as-received and Ar: $\mathrm{O}_{2} \mathrm{LPP}$ treated PE-WPC are shown in Figure 8 . The as-received PE-WPC had a rough surface and the polyethylene component was dominant in the surface. When PE-WPC was treated with Ar: $\mathrm{O}_{2}$ LPP for $20 \mathrm{~s}$, ablation was produced and the surface became smoother. The increase in treatment time favored the ablation and the creation of additional new surface roughness and porosity; both were more marked for a treatment time of $90 \mathrm{~s}$. On the other hand, the morphological changes in the Ar: $\mathrm{O}_{2}$ LPP-treated PE-WPC cannot be ascribed to thermal damage because the temperature of the just-treated composite was $35-40{ }^{\circ} \mathrm{C}$, which was measured with a non-contact electronic thermometer. 
The $180^{\circ}$ peel adhesion tests of the as-received and Ar: $\mathrm{O}_{2}$ LPP-treated PE-WPC/acrylic adhesive tape joints were carried out to verify if the surface modifications caused by $\mathrm{Ar}: \mathrm{O}_{2} \mathrm{LPP}$ surface treatment improved the adhesion of PE-WPC. For short treatment times, the adhesion values were close to that of the as-received PE-WPC ( $56 \mathrm{~N} / \mathrm{m}$ ) (Figure 9), and the increase in the Ar: $\mathrm{O}_{2} \mathrm{LPP}$ treatment time to $60-90 \mathrm{~s}$ produced an increase in adhesion $(102 \mathrm{~N} / \mathrm{m})$. Therefore, the optimal conditions of the Ar: $\mathrm{O}_{2}$ LPP surface treatment of PE-WPC is a treatment time of $90 \mathrm{~s}$.
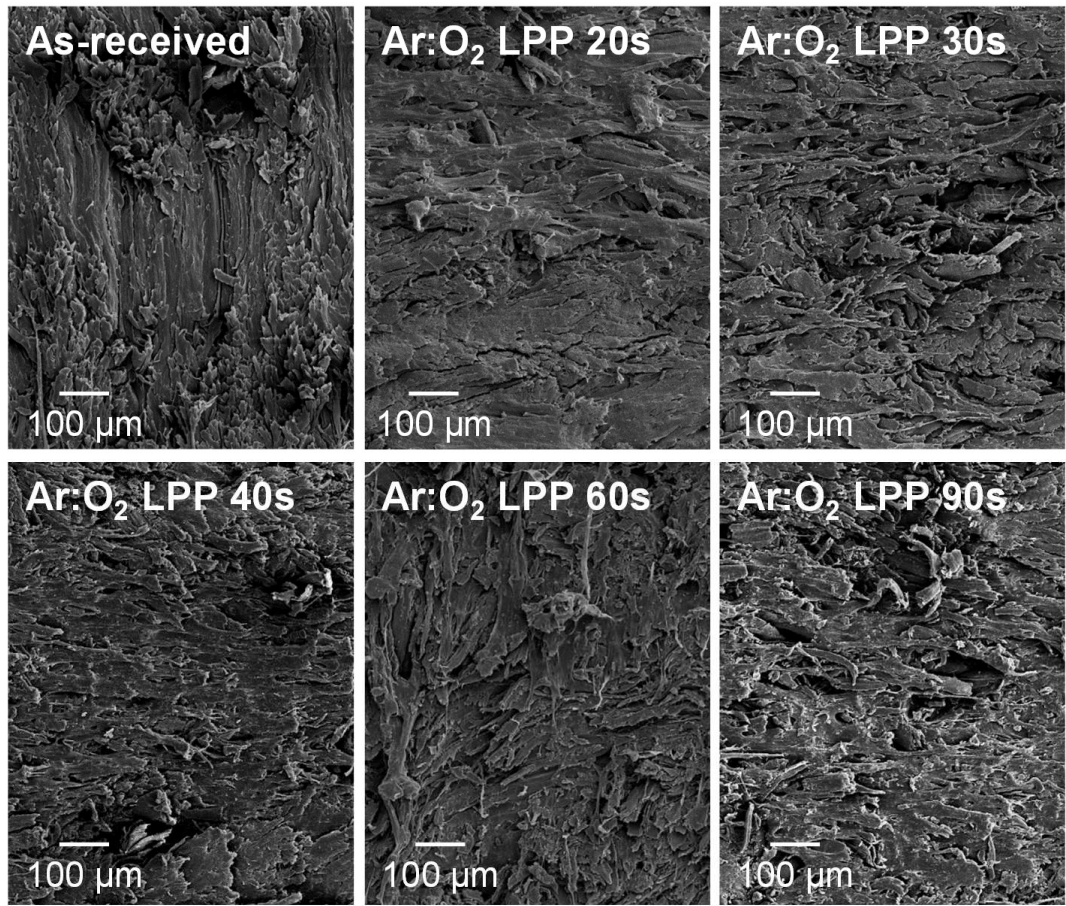

Figure 8. Scanning electron microscopy (SEM) micrographs of the as-received and Ar: $\mathrm{O}_{2}$ LPP-treated PE-WPC for different times.

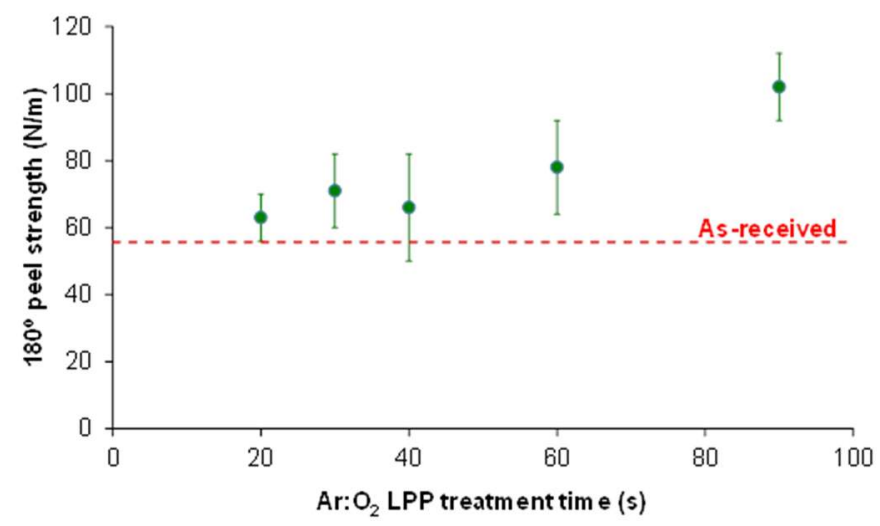

Figure 9. Variation in $180^{\circ}$ peel strength of as-received or Ar: $\mathrm{O}_{2} \mathrm{LPP}$-treated PE-WPC/acrylic adhesive tape joints as a function of the treatment time. All joints showed adhesion failure.

\subsection{Air Atmospheric Pressure Plasma Jet (APPJ) Treatment of PE-WPC}

A previous study by Yáñez-Pacios and Martín-Martínez [25] showed that a greater distance between the nozzle and the PE-WPC surface was not effective at improving its surface properties. Therefore, in this study, the APPJ treatment of PE-WPC was carried out using a distance of one $\mathrm{cm}$ between the nozzle and the PE-WPC surface, varying the platform speed between one and eight $\mathrm{m} / \mathrm{min}$. 
Figure 10a shows the region of $2800-3000 \mathrm{~cm}^{-1}$ of the ATR-IR spectra of the as-received and APPJ-treated PE-WPC. More marked chemical modifications were produced for low platform speeds (one to two $\mathrm{m} / \mathrm{min}$ ). The use of platform speeds of four to eight $\mathrm{m} / \mathrm{min}$ produced an important reduction in polyethylene in the PE-WPC surface, with a noticeable decrease in the intensity of the C-H bands at 2842, 2910, and $2942 \mathrm{~cm}^{-1}$, due to slight ablation. An increase in the surface treatment aggressiveness was observed by reducing the platform speed (one to two $\mathrm{m} / \mathrm{min}$ ) producing an increase in the intensity of the polyethylene bands, indicating the removal of the wood component from the PE-WPC surface and the exposure of polymer to the surface. The region of $1300-1800 \mathrm{~cm}^{-1}$ in the ATR-IR spectra (Figure 10b) more clearly demonstrates the decrease in the intensities of the polyethylene and wood bands for high-APPJ platform speeds (four to eight $\mathrm{m} / \mathrm{min}$ ), and the increase in the bands of the polyethylene at 1372 and $1451 \mathrm{~cm}^{-1}$ and the more intense band of the $\mathrm{C}=\mathrm{O}$ group at $1733 \mathrm{~cm}^{-1}$ due partly to surface oxidation for low-APPJ platform speeds (one to two $\mathrm{m} / \mathrm{min}$ ).

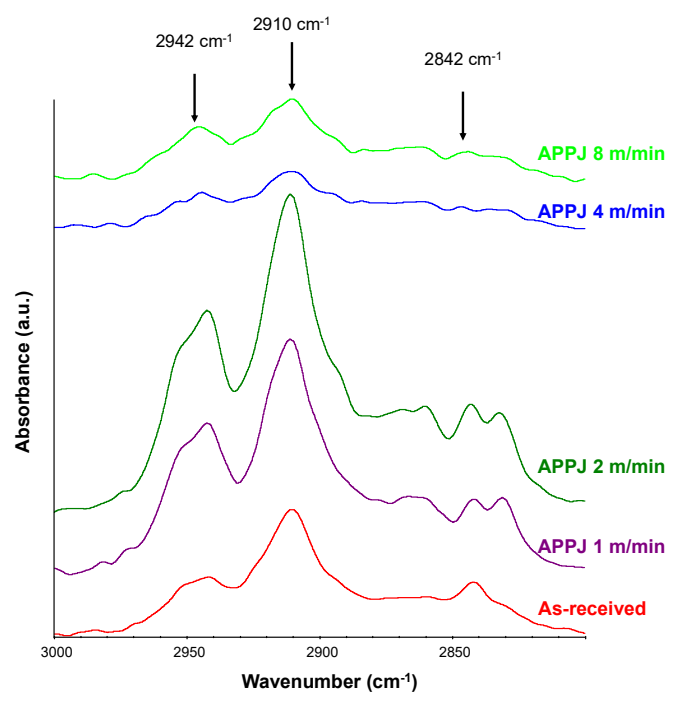

(a)

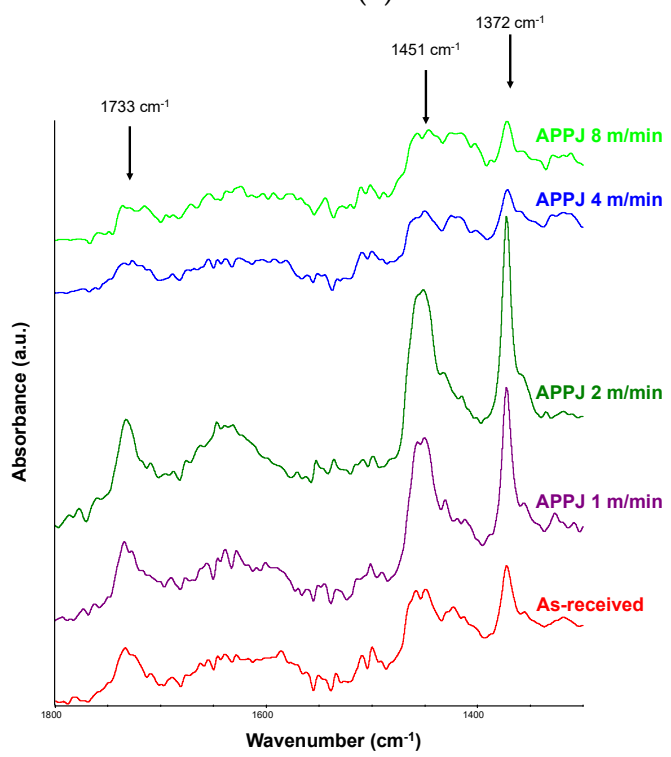

(b)

Figure 10. (a) Region of $2800-3000 \mathrm{~cm}^{-1}$ of the ATR-IR spectra of the as-received and APPJ-treated PE-WPC using different platform speeds. Germanium prism; (b) Region of $1300-1800 \mathrm{~cm}^{-1}$ of the ATR-IR spectra of the as-received and APPJ treated PE-WPC by using different platform speeds. Germanium prism. 
Figure 11 shows the evolution of the water contact angle values as a function of the APPJ platform speed. APPJ surface treatment increased the wettability and decreased the water contact angle value of PE-WPC more noticeably by decreasing the platform speed. For platform speeds of one and two $\mathrm{m} / \mathrm{min}$, the water contact angle values were low and nearly the same $\left(28-29^{\circ}\right)$, confirming the chemical modifications evidenced by ATR-IR spectroscopy. Similarly, the surface energy of PE-WPC increased with APPJ treatment. The increase was due to the increase of the polar component, which was more marked by decreasing the platform speed or by increasing the treatment time (Figure 12).

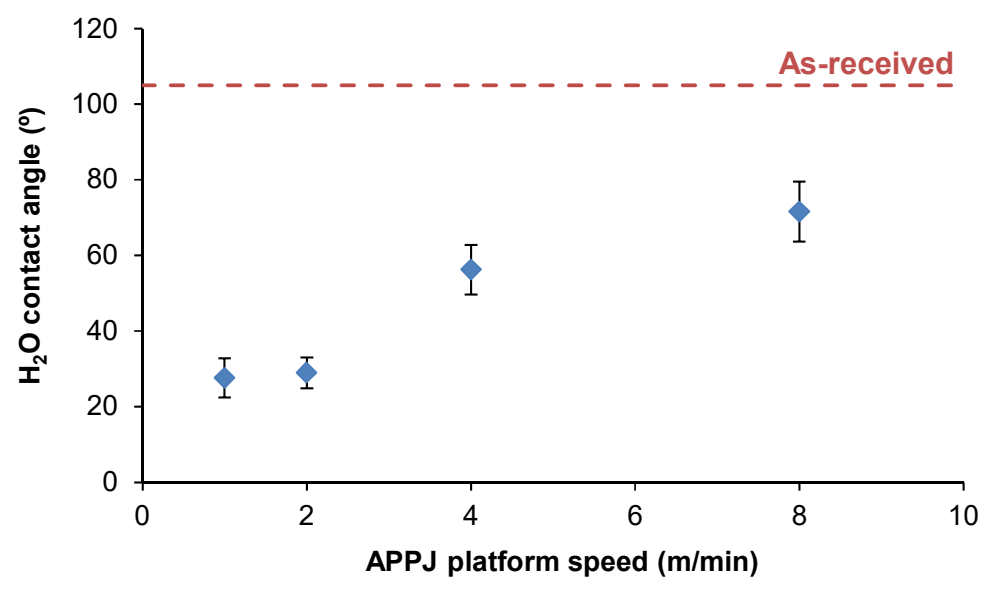

Figure 11. Variation in the water contact angle of the APPJ-treated PE-WPC as a function of the platform speed. The dashed line corresponds to the water contact angle of the as-received PE-WPC.

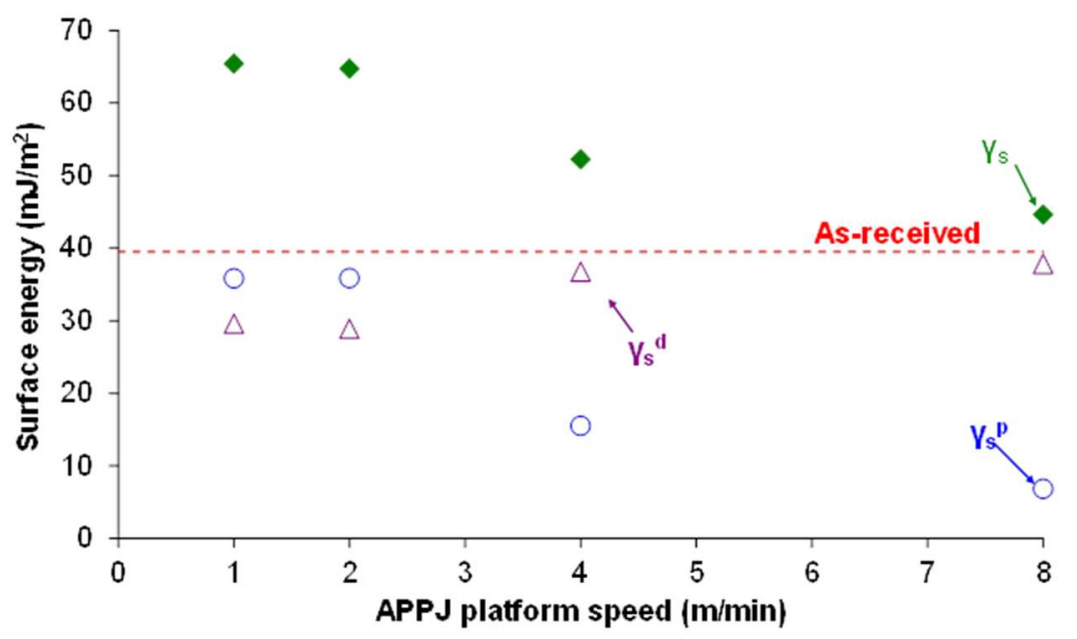

Figure 12. Variation in the surface energy $\left(\gamma_{s}\right)$ and their polar $\left(\gamma_{s}^{p}\right)$ and dispersive $\left(\gamma_{s}^{d}\right)$ components of the APPJ-treated PE-WPC as a function of the platform speed. The dashed line corresponds to the surface energy of the as-received PE-WPC that only corresponds to dispersive component.

The surface roughness of PE-WPC changed with APPJ treatment (Figure 13). The rough surface of the as-received PE-WPC was noticeably reduced by APPJ treatment, and to a greater extent by decreasing the platform speed. Some wood component removal on the PE-WPC surface was produced by treatment with the high speed of the platform, exposing some polymer to the outermost surface. The decrease in the speed of platform enhanced the exposure of polyethylene to the surface and the extent of ablation. On the other hand, the morphological changes on the APPJ-treated PE-WPC cannot be ascribed to thermal damage because the temperature during APPJ treatment was $45-60{ }^{\circ} \mathrm{C}$, which was measured with a non-contact electronic thermometer. Furthermore, the temperature of the just-treated composite was $35-40{ }^{\circ} \mathrm{C}$. 
Figure 14 shows the variation in the $180^{\circ}$ peel adhesion values for the as-received and APPJ-treated PE-WPC/acrylic adhesive tape joints as a function of the platform speed. For platform speeds of four and eight $\mathrm{m} / \mathrm{min}$, the adhesion properties were very similar to that of the as-received PE-WPC, but they improved when the length of the surface treatment increased. For platform speeds of one and two $\mathrm{m} / \mathrm{min}$, the highest $180^{\circ}$ peel strength was obtained at one $\mathrm{m} / \mathrm{min}$. Therefore, the optimal conditions for APPJ treatment of PE-WPC included a composite surface-nozzle distance of one $\mathrm{cm}$ and platform speed of one $\mathrm{m} / \mathrm{min}$.
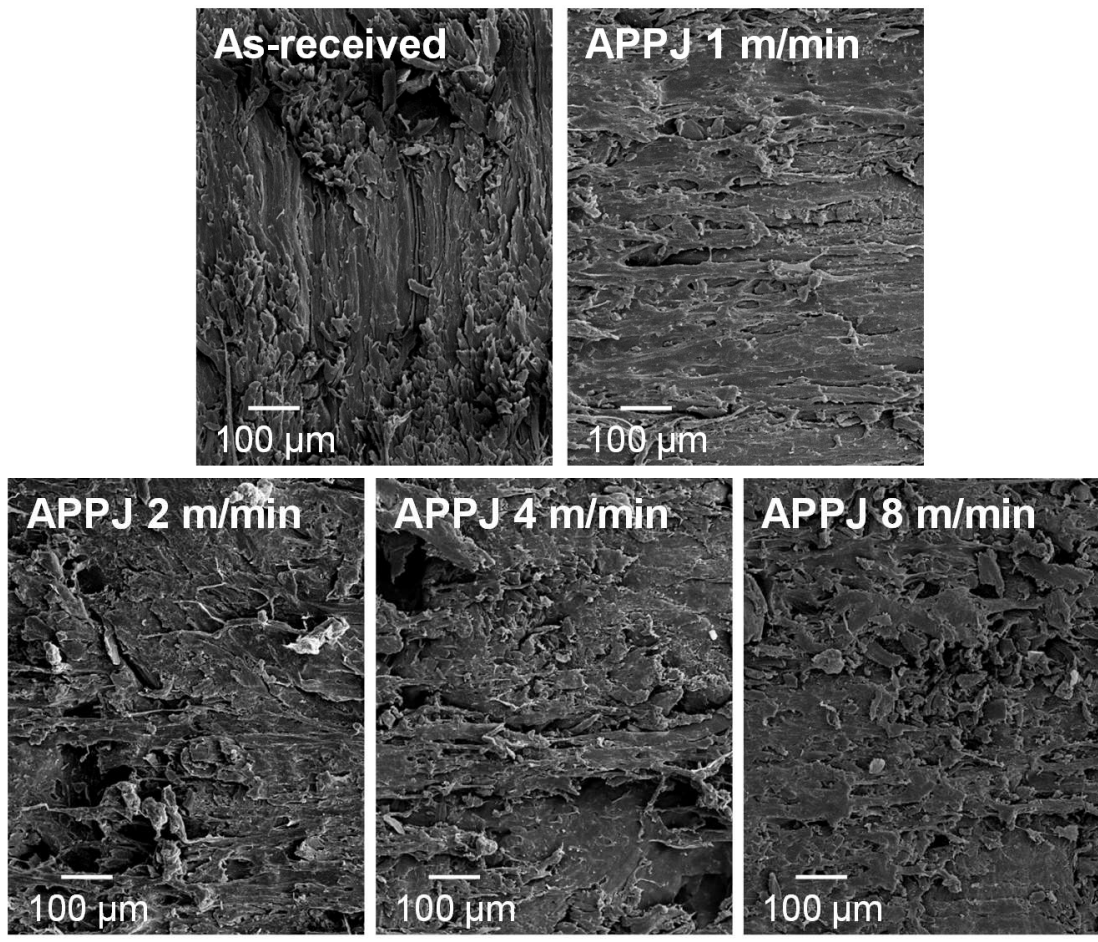

Figure 13. SEM micrographs of the as-received and APPJ-treated PE-WPC with different platform speeds.

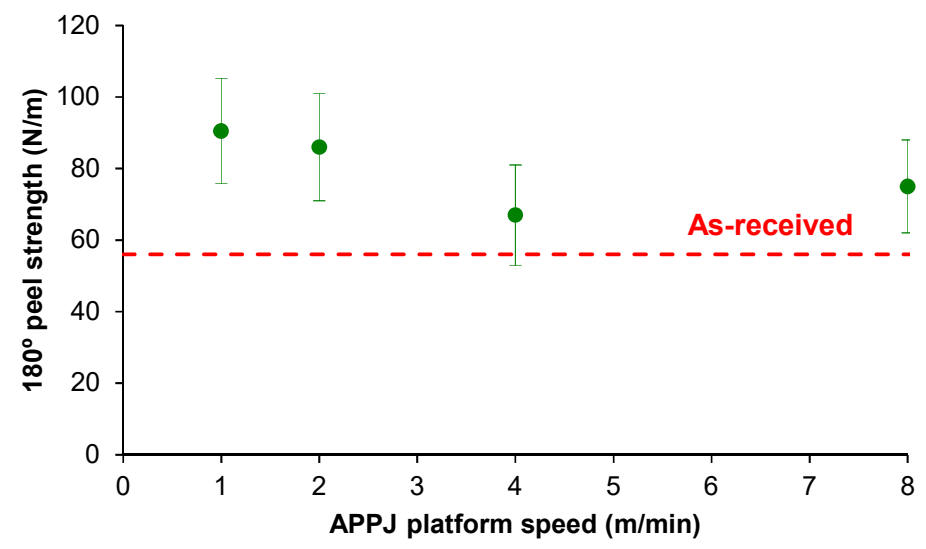

Figure 14. Variation in $180^{\circ}$ peel strength of as-received and APPJ-treated PE-WPC/acrylic adhesive tape joints as a function of the platform speed. All joints showed an adhesion failure.

\subsection{Comparison of the Ar: $\mathrm{O}_{2} L P P$ and APPJ Treatments of PE-WPC}

In this section, the surface modifications and adhesion of PE-WPC treated with plasmas under the optimal conditions are compared. The optimal conditions were Ar: $\mathrm{O}_{2} \mathrm{LPP}$ treatment for $90 \mathrm{~s}$ and air APPJ treatment using PE-WPC surface-nozzle distance of one $\mathrm{cm}$ and platform speed of one $\mathrm{m} / \mathrm{min}$. 
Figure 15 shows the ATR-IR spectra of the Ar: $\mathrm{O}_{2}$ LPP- and APPJ-treated PE-WPC. The ATR-IR spectra showed that the APPJ treatment produced more marked chemical changes in the PE-WPC surface than Ar: $\mathrm{O}_{2}$ LPP treatment, because of the more intense C-H stretching bands at $2830-2940 \mathrm{~cm}^{-1}$ and the more intense bands of methylene groups at 1373-1455 $\mathrm{cm}^{-1}$, both due to polyethylene. Furthermore, the ATR-IR spectrum of the APPJ-treated PE-WPC showed a lower intensity of the -OH band at $3350 \mathrm{~cm}^{-1}$ due to the wood component, and a greater surface oxidation extent, more intense $\mathrm{C}=\mathrm{O}$ stretching band at $1735 \mathrm{~cm}^{-1}$. Therefore, the extent of the chemical modification of PE-WPC is more important when treated with APPJ than with Ar: $\mathrm{O}_{2}$ LPP.



Figure 15. ATR-IR spectra of the as-received and plasma treated PE-WPC. Germanium prism.

The plasma treatment noticeably increased the surface energy of PE-WPC (Figure 16). This increase was due to the polar component. Although the extent of the chemical modifications in Ar: $\mathrm{O}_{2}$ LPP-treated PE-WPC were less marked than in APPJ-treated composite, both plasma treatments produced somewhat similar surface energy and similar polar and dispersive components. The $\mathrm{Ar}: \mathrm{O}_{2}$ LPP treatment exposed less polyethylene polymer to the PE-WPC surface and, therefore, less oxidation was produced. However, the surface energy can also be affected by the changes in the PE-WPC surface topography and roughness produced by both plasmas.

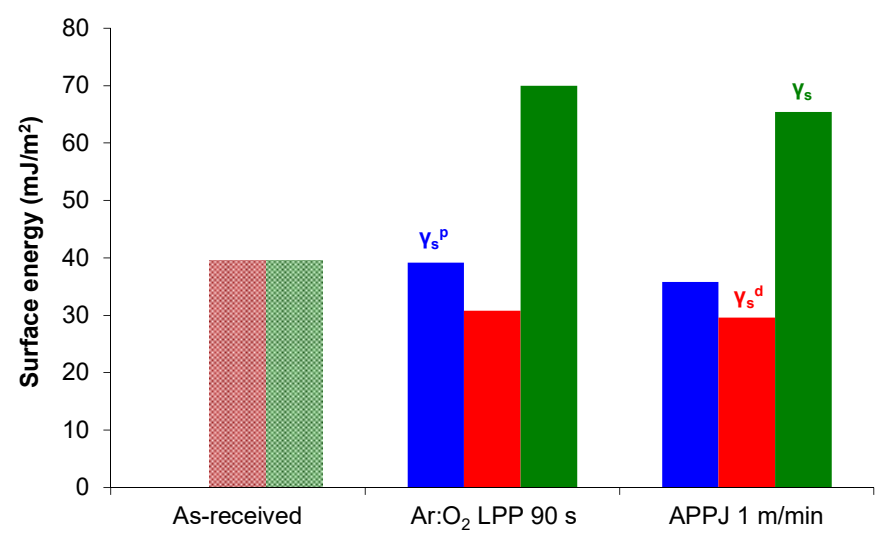

Figure 16. Surface energy and their polar and dispersive components of the as-received and plasma-treated PE-WPC. 
Figure 17 shows the lesser extent of ablation in APPJ-treated PE-WPC than in Ar: $\mathrm{O}_{2}$ LPP-treated composite. The roughness of the Ar: $\mathrm{O}_{2}$ LPP-treated PE-WPC was more similar to the as-received PE-WPC; different surface topography was obtained in APPJ-treated composite. Therefore, the APPJ treatment removed less wood component from the PE-WPC surface than Ar: $\mathrm{O}_{2}$ LPP treatment, which must affect the surface energy.
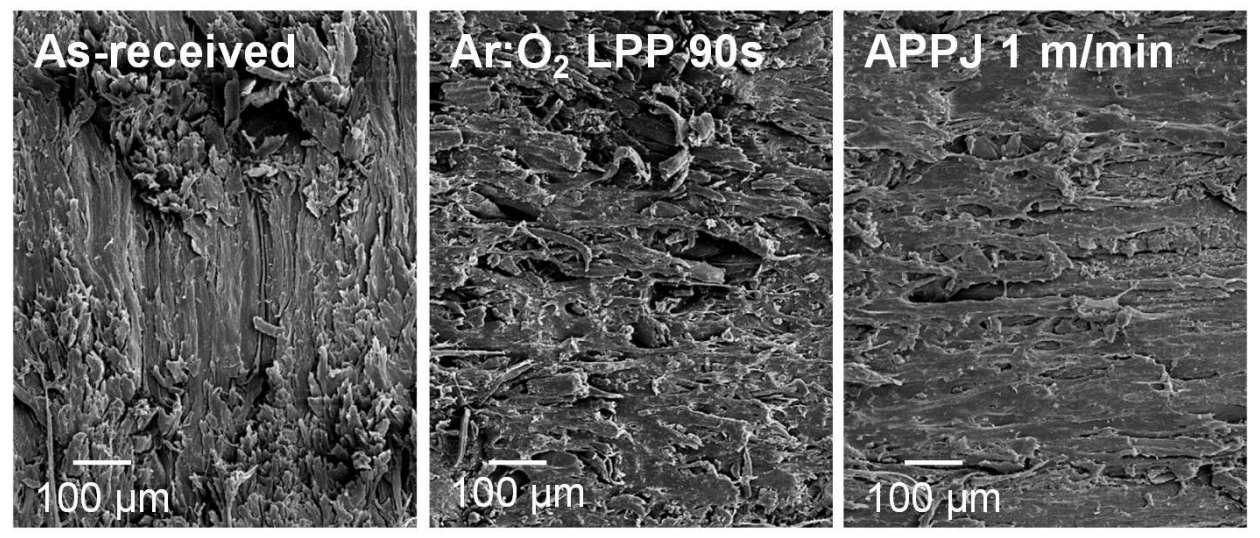

Figure 17. SEM micrographs of the as-received and plasma-treated PE-WPC.

According to the previous results, the extent of surface oxidation produced on the plasma-treated PE-WPC was less important than the extent of physical ablation. The extent of physical ablation in PE-WPC produced by the plasma treatments was assessed by determining the weight losses produced during the treatment by using a precise analytical balance Cobos AX-200 (Cobos Precisión S.L., Barcelona, Spain) and by thermogravimetric analysis (TGA). The assessment of the extent of ablation of different surface treated polymers from weight loss has been established $[37,38]$. The PE-WPC pieces were weighted before and after plasma treatment and the weight losses were obtained by averaging the results obtained with five measurements per sample. The weight loss produced in the $\mathrm{Ar}: \mathrm{O}_{2}$ LPP-treated PE-WPC was $0.59 \pm 0.15 \%$, whereas the weight loss of the air APPJ-treated PE-WPC was $0.04 \pm 0.01 \%$, confirming the most pronounced ablation of PE-WPC was produced by the Ar: $\mathrm{O}_{2}$ LPP treatment.

The extent of ablation of the plasma-treated PE-WPC was also assessed by TGA. Figure 18a shows the variation in weight as a function of temperature for the as-received and plasma-treated PE-WPC. Whereas the TGA thermograms of the as-received and APPJ treated PE-WPC were quite similar, the Ar: $\mathrm{O}_{2}$ LPP-treated PE-WPC showed higher weight loss, mainly in the region between 350 and $400{ }^{\circ} \mathrm{C}$. The curves of the derivative of the weight as a function of temperature (Figure 18b) show the existence of three main thermal degradations in the as-received and plasma-treated PE-WPC corresponding to water/moisture loss (maximum temperature of decomposition at $52-78{ }^{\circ} \mathrm{C}$ ), decomposition of the wood component (maximum temperature of decomposition at $344{ }^{\circ} \mathrm{C}$ ), and decomposition of the polyethylene component (maximum temperature of decomposition at $449-450{ }^{\circ} \mathrm{C}$ ). The thermal decompositions of the wood and polyethylene component of the as-received and plasma-treated PE-WPC were produced at the same temperature but the water removal was produced at higher temperatures in APPJ-treated PE-WPC, likely due to the removal of weak hydroxyl groups produced by the treatment. The weight losses corresponding to the three thermal decompositions are provided in Table 1, in which the weight loss due to the wood component is higher and that of the polyethylene component is lower in Ar: $\mathrm{O}_{2}$ LPP-treated PE-WPC than in APPJ-treated PE-WPC. Therefore, the more pronounced ablation of Ar: $\mathrm{O}_{2}$ LPP-treated PE-WPC was confirmed. 


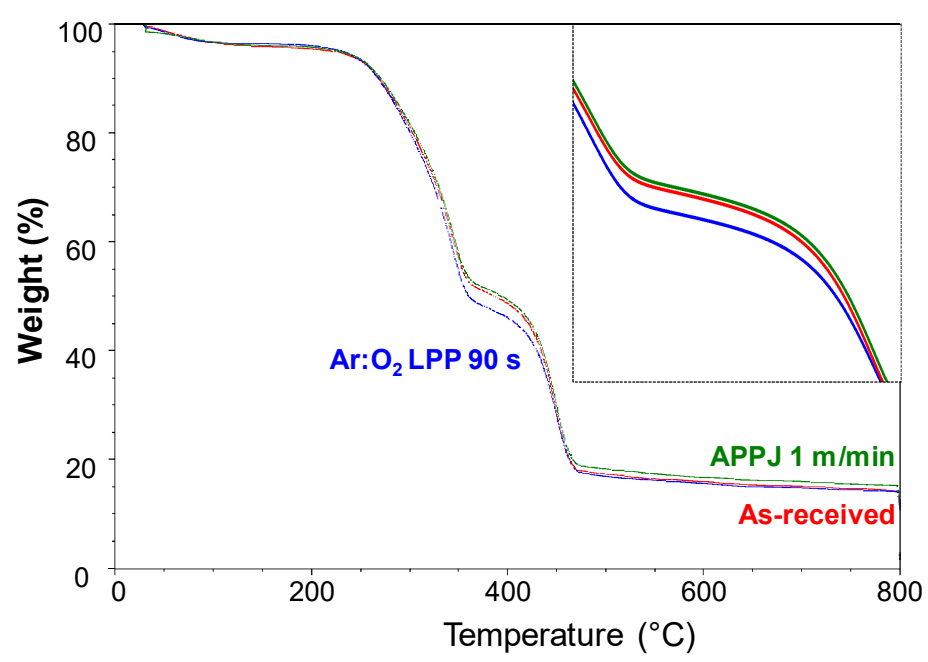

(a)

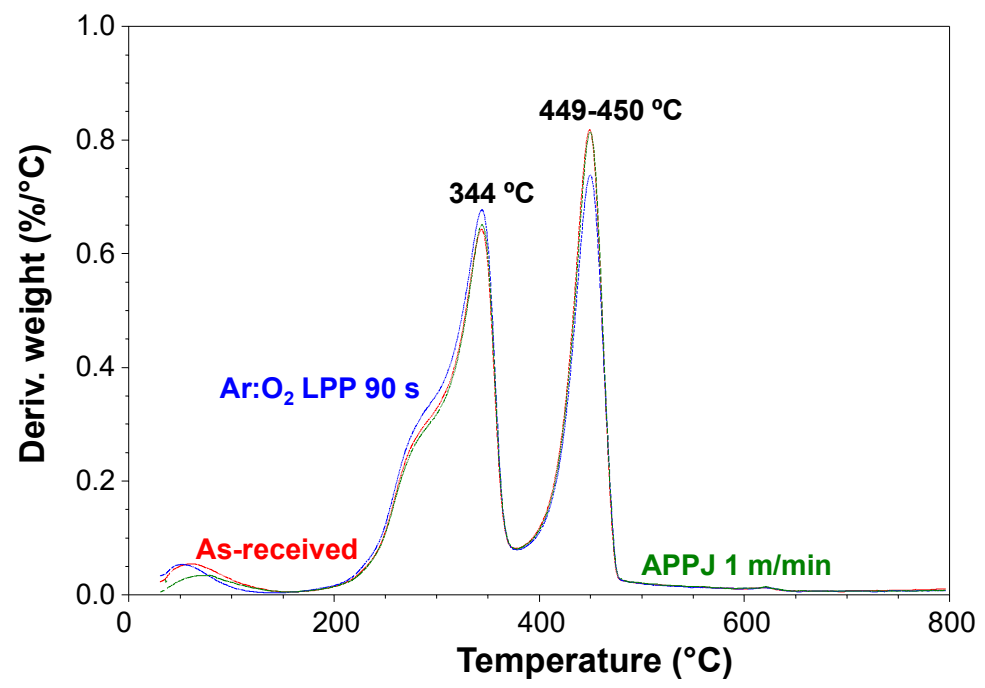

(b)

Figure 18. (a) Variation in weight as function of the temperature of the as-received and plasma-treated PE-WPC through thermogravimetric analysis (TGA) experiments; (b) Variation in derivative of the weight as function of the temperature of the as-received and plasma-treated PE-WPC through TGA experiments.

Table 1. Weight losses of the thermal decompositions of the as-received and plasma treated polyethylene wood plastic composite (PE-WPC) obtained with thermogravimetric analysis (TGA) experiments.

\begin{tabular}{cccc}
\hline Surface Treatment & Weight Loss (\%) at $\mathbf{5 2 - 7 8}{ }^{\circ} \mathbf{C}$ & Weight Loss (\%) at $\mathbf{3 4 4}{ }^{\circ} \mathbf{C}$ & Weight Loss (\%) at $\mathbf{4 4 9 - 4 5 0}{ }^{\circ} \mathbf{C}$ \\
\hline As-received & 4 & 45 & 35 \\
Ar: $\mathrm{O}_{2}$ LPP 90 s & 3 & 49 & 32 \\
APPJ 1 m/min & 3 & 45 & 35 \\
\hline
\end{tabular}

The $180^{\circ}$ peel strength values of the as-received and plasma-treated PE-WPC/acrylic adhesive tape joints are shown in Figure 19. The plasma treatment increased the adhesion of PE-WPC; the improvement was somewhat higher when the Ar: $\mathrm{O}_{2}$ LPP treatment was used. This slightly higher $180^{\circ}$ peel strength can be ascribed to the existence of porosity and the higher roughness of the PE-WPC surface that should increase the mechanical interlocking with the acrylic adhesive tape. 
In general, similar adhesion was obtained in the joints made with PE-WPC treated with Ar: $\mathrm{O}_{2} \mathrm{LPP}$ and air APPJ under optimal experimental conditions.

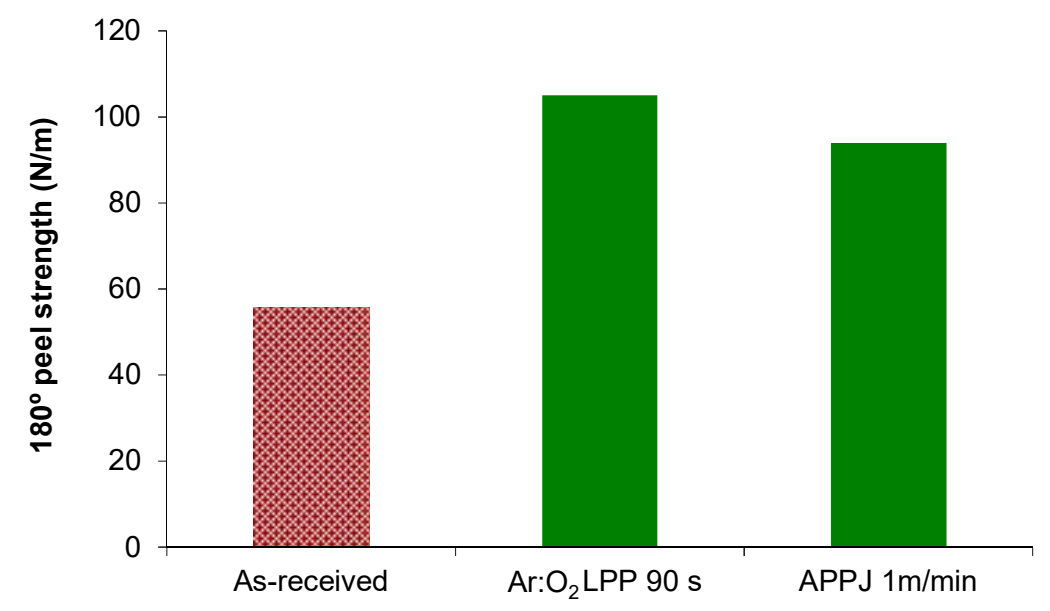

Figure 19. The $180^{\circ}$ peel strength values of as-received and plasma-treated PE-WPC/acrylic adhesive joints. An adhesion failure always occurred.

\subsection{Ageing of Plasma Treated PE-WPC}

The surface modifications of the plasma-treated PE-WPC may last over time because of the presence of polyethylene on the outermost surface. The influence of ageing on the adhesion of plasma-treated PE-WPC was studied and two different ageing experiments were carried out.

After plasma treatment of PE-WPC, it was left at $24{ }^{\circ} \mathrm{C}$ and $40 \%$ relative humidity and the adhesive joints were created between one hour and seven days after treatment (Figure 4a). Figure 20a shows the variation in the $180^{\circ}$ peel strength as a function of ageing time. During the first day after APPJ treatment, the adhesion of the APPJ-treated PE-WPC was maintained but a gradual decrease in the $180^{\circ}$ peel strength was produced by increasing the ageing time. After six days, the $180^{\circ}$ peel strength was similar to that of the joint made with the as-received PE-WPC. On the other hand, for the joints created with the Ar: $\mathrm{O}_{2}$ LPP-treated PE-WPC, an abrupt decrease in adhesion value was observed one day after treatment, and the adhesion did not vary for longer ageing times, being the same as that of the joint made with the as-received PE-WPC. Therefore, faster hydrophobic recovery was produced in the joints made with Ar: $\mathrm{O}_{2}$ LPP-treated PE-WPC, likely due to the lower extent of chemical modifications than in the APPJ-treated composite. After six days, the adhesion of the joints created with the plasma treated PE-WPC was the same and corresponds to the adhesion of the joint made with the as-received PE-WPC, indicating complete hydrophobic recovery, irrespective of the type of plasma used.

Ageing of the plasma-treated PE-WPC was also studied by treating the composite and creating the adhesive joint immediately after plasma treatment; $180^{\circ}$ peel tests were carried out at different times (between one hour and six days) after joint formation (Figure $4 \mathrm{~b}$ ). Figure 20b shows that both plasma treatments showed similar variation in the adhesion as a function of ageing time. The adhesion increased up to one day after joint formation and was constant with increasing ageing time thereafter. In fact, an adhesion value of $140 \mathrm{~N} / \mathrm{m}$ was obtained, irrespective of the kind of plasma treatment. Therefore, hydrophobic recovery was inhibited and even an additional interaction between the polar acrylic tape and the polar surface of the plasma-treated PE-WPC was produced $24 \mathrm{~h}$ after joint formation. The nature of these interactions will be investigated in the future. 


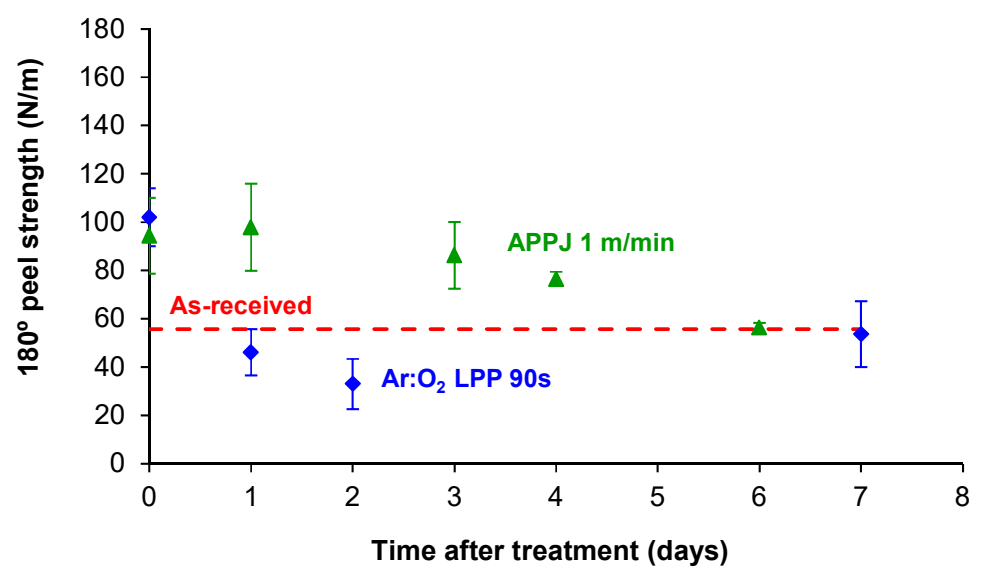

(a)

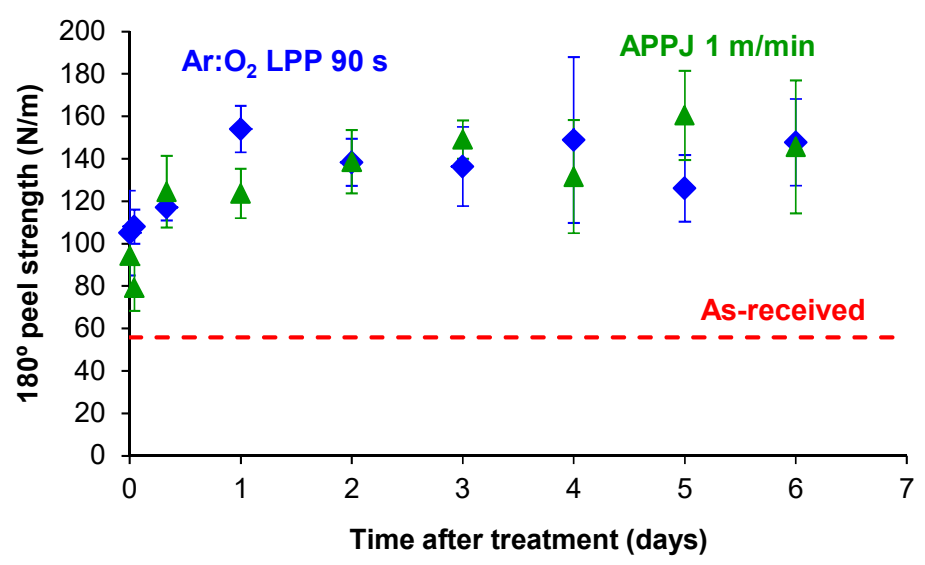

(b)

Figure 20. (a) Variation in the $180^{\circ}$ peel strength of plasma treated PE-WPC/acrylic adhesive tape joints as a function of the time after treatment. Joints were created at different times after plasma treatment and they were tested one hour after joint formation. All joints showed an adhesion failure. The dashed line corresponds to the $180^{\circ}$ peel strength of the as-received PE-WPC/acrylic adhesive tape joint; (b) Variation in the $180^{\circ}$ peel strength of plasma treated PE-WPC/acrylic adhesive tape joints as a function of the time after treatment. Joints were created immediately after plasma treatment and they were tested at different times after joint formation. All joints showed an adhesion failure. The dashed line corresponds to the $180^{\circ}$ peel strength of as-received PE-WPC/acrylic adhesive tape joint.

\section{Conclusions}

The optimal conditions for improving the surface properties and adhesion of PE-WPC were Ar: $\mathrm{O}_{2}$ LPP-treatment for $90 \mathrm{~s}$, and air APPJ surface treatment at a distance between the nozzle and the PE-WPC surface of one centimeter, and speed of platform of one meter per minute.

Both plasma treatments produced similar chemical modifications and caused ablation of the PE-WPC surface. The extent of the chemical modifications was more pronounced by treatment with APPJ and the extent of ablation was more important for treatment with Ar: $\mathrm{O}_{2} \mathrm{LPP}$. Furthermore, both plasma treatments modified the surface roughness of the PE-WPC; a smoother surface was produced by treating with APPJ and greater roughness and porosity were created by treatment with Ar: $\mathrm{O}_{2}$ LPP. Because of the combination of the chemical modifications and roughness, the surface energies of the plasma-treated PE-WPC increased noticeably and they were similar when they were treated with APPJ and Ar: $\mathrm{O}_{2}$ LPP under optimal conditions. The increase was mainly due to the increase in the polar component. Consequently, the $180^{\circ}$ peel strength of the joints made with 
plasma-treated PE-WPCs notably increased from $56 \mathrm{~N} / \mathrm{m}$ for the joint made with the as-received PE-WPC to $92-102 \mathrm{~N} / \mathrm{m}$ for the joints made with plasma-treated PE-WPCs. Similar improvements in adhesion were obtained by treatment with APPJ and Ar: $\mathrm{O}_{2}$ LPP.

Ageing of the adhesive joints over time was studied by surface treatment of PE-WPC with plasmas, allowing the treated surface to be exposed at $24{ }^{\circ} \mathrm{C}$ and $40 \%$ relative humidity for different times. Although adhesion was maintained in the joints made with APPJ-treated PE-WPC for one to three days, an important decline was observed after one day ageing in the joints made with $\mathrm{Ar}: \mathrm{O}_{2}$ LPP-treated PE-WPC. After six days, similar adhesion for the joint made with the as-received PE-WPC was obtained, indicating that full hydrophobic recovery was produced, irrespective of the kind of plasma used. If the adhesive joints were made with the just plasma-treated PE-WPC, one day after joint formation, the adhesion increased to $140 \mathrm{~N} / \mathrm{m}$, similarly for the joints made with $\mathrm{Ar}: \mathrm{O}_{2} \mathrm{LPP}$ and APPJ, and the $180^{\circ}$ peel strength was maintained up to six days. Therefore, hydrophobic recovery was completely avoided.

Author Contributions: A.J.Y.-P. designed the experiments and analyzed the data. J.M.M.-M. conceived the experiments, analyzed the data and wrote the paper.

Acknowledgments: Financial support from Spanish Ministry of Economy and Competitiveness-grant No. IPT-2011-1454-020000, INNPACTO research program—is acknowledged.

Conflicts of Interest: The authors declare no conflicts of interest.

\section{References}

1. Gramlich, W.M.; Gardner, D.J.; Neivandt, D.J. Surface treatments of wood-plastic composites (WPC) to improve adhesion. J. Adhes. Sci. Technol. 2006, 20, 1873-1887. [CrossRef]

2. Kraus, E.; Baudrit, B.; Heidemeyer, P.; Bastian, M.; Stoyanov, O.V.; Starostina, I.A. Problems in adhesion bonding of WPC. Polym. Res. J. 2015, 9, 327-335.

3. Ryntz, R.A. Adhesion to Plastics—Molding and Paintability, 1st ed.; Global Press: Chicago, IL, USA, 1998; p. 112, ISBN-13 978-1890086022.

4. Dimitriou, A.; Hale, M.D.; Spear, M.J. The effect of four methods of surface activation for improved adhesion of wood polymer composites (WPC). Int. J. Adhes. Adhes. 2016, 68, 188-194. [CrossRef]

5. Oporto, G.S.; Gardner, D.J.; Bernhardt, G.; Neivandt, D.J. Characterizing the mechanism of improved adhesion of modified wood plastic composite (WPC) surfaces. J. Adhes. Sci. Technol. 2007, 21, 1097-1116. [CrossRef]

6. Moghadamzadeh, H.; Rahimi, H.; Asadollahzadeh, M.; Hemmati, A.R. Surface treatment of wood polymer composites for adhesive bonding. Int. J. Adhes. Adhes. 2011, 31, 816-821. [CrossRef]

7. Akhtarkhavari, A.; Kortschot, M.T.; Spelt, J.K. Adhesion and durability of latex paint on wood fiber reinforced polyethylene. Prog. Org. Coat. 2004, 49, 33-41. [CrossRef]

8. Yáñez-Pacios, A.J.; Martín-Martínez, J.M. Surface modification and adhesion of wood-plastic composite (WPC) treated with UV/ozone. Compos. Interfaces 2017, 25, 127-149. [CrossRef]

9. Egitto, F.D.; Matienzo, L.J. Plasma modification of polymer surfaces for adhesion improvement. J. Res. Dev. 1994, 38, 423-439. [CrossRef]

10. Foerch, R.; Mcintyre, N.S.; Sodhi, R.N.S.; Hunter, D.H. Nitrogen plasma treatment of polyethylene and polystyrene in a remote plasma reactor. J. Appl. Polym. Sci. 1990, 40, 1903-1915. [CrossRef]

11. Choi, D.M.; Park, C.K.; Cho, K.; Park, C.E. Adhesion improvement of epoxy resin/polyethylene joints by plasma treatment of polyethylene. Polymer 1997, 38, 6243-6249. [CrossRef]

12. Sanchis, M.R.; Blanes, V.; Blanes, M.; Garcia, D.; Balart, R. Surface modification of low density polyethylene (LDPE) film by low pressure $\mathrm{O}_{2}$ plasma treatment. Eur. Polym. J. 2006, 42, 1558-1568. [CrossRef]

13. Dowling, D.P.; O'Neill, F.T.; Langlais, S.J.; Law, V.J. Influence of DC pulsed atmospheric pressure plasma jet processing conditions on polymer activation. Plasma Process. Polym. 2011, 8, 717-727. [CrossRef]

14. Noeske, M.; Degenhardt, J.; Strudthoff, S.; Lommastzsch, U. Plasma jet treatment of five polymers at atmospheric pressure: Surface modifications and the relevance of adhesion. Int. J. Adhes. Adhes. 2004, 24, 171-177. [CrossRef] 
15. Lynch, J.B.; Spence, P.D.; Baker, D.E.; Postlethwaite, T.A. Atmospheric pressure plasma treatment of polyethylene via a pulse dielectric barrier discharge: Comparison using various gas compositions versus corona discharge in air. J. Appl. Polym. Sci. 1999, 71, 319-331. [CrossRef]

16. Carrino, L.; Moroni, G.; Polini, W. Cold plasma treatment of polypropylene surface: A study on wettability and adhesion. J. Mater. Process. Tech. 2002, 121, 373-382. [CrossRef]

17. Di, M.; Liu, Y. Stability and ageing of plasma treated wood/polyethylene composites surfaces. Adv. Mat. Res. 2011, 150-151, 829-833. [CrossRef]

18. Tao, Y.; Di, M. Study on plasma treatment and adhesion of wood/polyethylene composites. Appl. Mech. Mater. 2011, 66-68, 911-915. [CrossRef]

19. Tao, Y.; Wang, H.; Di, M. Evolution of surface properties for plasma treated wood/polyethylene composites under water soaking. Mat. Eng. 2012, 2, 94-98. [CrossRef]

20. Wolkenhauer, A.; Avramidis, G.; Hauswald, E.; Militz, H.; Viöl, W. Plasma treatment of wood-plastic composites to enhance their adhesion properties. J. Adhes. Sci. Technol. 2008, 22, 2025-2037. [CrossRef]

21. Liu, Y.; Tao, Y.; Lv, X.; Zhang, Y.; Di, M. Study on the surface properties of wood/polyethylene composites treated under plasma. Appl. Surf. Sci. 2010, 257, 1112-1118. [CrossRef]

22. Hünnekens, B.; Peters, F.; Avramidis, G.; Krause, A.; Militz, H.; Viöl, W. Plasma treatment of wood-polymer composites: A comparison of three different discharge types and their effect on surface properties. J. Appl. Polym. Sci. 2016, 133, 43376. [CrossRef]

23. Oporto, G.S.; Gardner, D.J.; Bernhardt, G.; Neivandt, D.J. Forced air plasma treatment (FAPT) of hybrid wood plastic composite (WPC)-fiber reinforced plastic (FRP) surfaces. Compos. Interfaces 2009, 16, 847-867. [CrossRef]

24. Hämäläinen, K.; Kärki, T. Effects of atmospheric plasma treatment on the surface properties of wood-plastic composites. Adv. Mater. Res. 2013, 718-720, 176-185. [CrossRef]

25. Yáñez-Pacios, A.J.; Martín-Martínez, J.M. Surface modification and improved adhesion of wood-plastic composites (WPC) made with different polymers by treatment with atmospheric pressure rotating plasma jet. Int. J. Adhes. Adhes. 2017, 77, 204-213. [CrossRef]

26. Gupta, B.S.; Laborie, M.-P.G. Surface activation and adhesion properties of wood-fiber reinforced thermoplastic composites. J. Adhes. 2007, 83, 939-955. [CrossRef]

27. Constantinescu, G.; Totolin, M.; Cojocariu, A.; Popa, V.I.; Vasile, C. Study of the surface properties of some polyolefin/lignocellulosic composites treated by plasma. Cell. Chem. Technol. 2007, 41, 463-472.

28. Yáñez-Pacios, A.J.; Martín-Martínez, J.M. Improved surface and adhesion properties of wood-polyethylene composite by treatment with argon-oxygen low pressure plasma. Plasma Chem. Plasma Process. 2018. [CrossRef]

29. Behnisch, J.; Holländer, A.; Zimmermann, H. Factors influencing the hydrophobic recovery of oxygen-plasmatreated polyethylene. Surf. Coat. Tech. 1993, 59, 356-358. [CrossRef]

30. Mortazavi, M.; Nosonovsky, M. A model for diffusion-driven hydrophobic recovery in plasma treated polymers. Appl. Surf. Sci. 2012, 258, 6876-6883. [CrossRef]

31. Bormashenko, E.; Chaniel, G.; Grynyov, R. Towards understanding hydrophobic recovery of plasma treated polymers: Storing in high polarity liquids suppresses hydrophobic recovery. Appl. Surf. Sci. 2013, 273, 549-553. [CrossRef]

32. Della Volpe, C.; Fambri, L.; Fenner, R.; Migliaresi, C.; Pegoretti, A. Air plasma treated polyethylene fibres: Effect of time and temperature ageing on fibre surface properties and on fibre/matrix adhesion. J. Mater. Sci. 1994, 29, 3919-3925. [CrossRef]

33. Sun, J.; Qiu, Y.P. The effects of gas composition on the atmospheric pressure plasma jet modification of polyethylene films. Plasma Sci. Technol. 2015, 17, 402-408. [CrossRef]

34. Ba, O.M.; Marmey, P.; Anselme, K.; Duncan, A.C.; Ponche, A. Surface composition XPS analysis of a plasma treated polystyrene: Evolution over long storage periods. Colloids Surf. B 2016, 145, 1-7. [CrossRef] [PubMed]

35. Hünnekens, B.; Krause, A.; Militz, H.; Viöl, W. Hydrophobic recovery of atmospheric pressure plasma treated surfaces of Wood-Polymer Composites (WPC). Eur. J. Wood Prod. 2017, 75, 761-766. [CrossRef]

36. Cantos-Delegido, B.; Martín-Martínez, J.M. Treatment with $\mathrm{Ar}-\mathrm{O}_{2}$ low-pressure plasma of vulcanized rubber sole containing noticeable amount of processing oils for improving adhesion to upper in shoe industry. J. Adhes. Sci. Technol. 2015, 29, 1301-1314. [CrossRef] 
37. Slepicka, P.; Michaljanicová, I.; Svorcík, V. Controlled biopolymer roughness induced by plasma and excimer laser treatment. eXPRESS Polym. Lett. 2013, 7, 950-958. [CrossRef]

38. Slepicka, P.; Trostová, S.; Slepicková, N.; Kasalková, S.; Kolská, Z.; Sajdl, P.; Svorcík, V. Surface modification of biopolymers by argon plasma and thermal treatment. Plasma Process. Polym. 2012, 9, 197-206. [CrossRef] 